\title{
RESPONSABILIDAD (PENAL) ADOLESCENTE, RESPONSABILIDAD \\ DEL PSICOANALISTA: ÉTICA Y DESEO COMO POSIBILIDAD PARA \\ UNA CLÍNICA PSICOANALÍTICA
}

Nelson Espinosa Bahamondes - Universidad Diego Portales

Nelson Espinosa Bahamondes

Psicólogo, Magister en Psicología Clínica de Adultos, mención Psicoanalisis, Universidad de Chile

Docente Magister en Psicología mención Teoría y Clínica Psicoanalítica, Universidad Diego Portales Miembro Fundación Grupo Psicoanalítico Plus

\section{Correspondencia}

Nelson Espinosa Bahamondes

nelson.espinosa@udp.cl

Grajales 1898, Santiago 


\title{
Resumen
}

El siguiente artículo interroga la noción de responsabilidad, por un lado, del adolescente y por otro, del psicoanalista en lo que atañe a una clínica psicoanalítica atravesada por actos delictivos adolescentes. ¿Qué puntos de encuentros serían posibles entre responsabilidad penal adolescente, responsabilidad subjetiva y responsabilidad del psicoanalista?

El artículo plantea una revisión teórica-conceptual basada en los aportes del psicoanálisis, puntualmente desde la perspectiva de Freud, Winnicott y Lacan, estableciendo un trayecto que va de la noción de culpa inconsciente, pasando por el papel del ambiente, y abordando el lugar del acting out en la clínica psicoanalítica con adolescentes. Dicho recorrido distingue la dimensión jurídica y simbólica de la ley, desembocando en el posicionamiento ético y deseante del analista como condiciones de posibilidad para dicha clínica.

Palabras clave: responsabilidad penal adolescente; responsabilidad del analista; acto delictivo; acting out; ética, deseo

\begin{abstract}
The following article examines the notion of responsibility in both the teenager and the psychoanalyst, about a psychoanalytic practice intersected by juvenile criminal acts. Which common grounds would be possible to make between the notions of juvenile criminal responsibility, subjective responsibility and the psychoanalyst's responsibility?

This article offers a bibliographic review of psychoanalytic theory, most notably from the perspectives of Freud, Winnicott and Lacan, in order to approach the notions of unconscious guilt, the role of the environment, and the role that acting out has in the context of the psychoanalytic practice with young people. The article distinguishes between the juridic and symbolic dimensions of the law, in order to propose an ethical and desiring position of the analyst as one of the main conditions for such clinical practice to be possible.
\end{abstract}

Key words: juvenile criminal responsibility; analyst's responsibility; criminal act; acting out; ethics; desire 


\section{Introducción}

La problemática referida a la delincuencia juvenil constituye un ámbito conflictivo de abordar. Concierne a sujetos reconocidos e identificados por el aparataje estatal como "menores" es decir, situados como tales desde una discursividad adultocéntrica, cuestión que supondría múltiples interrogantes. Desde esta problemática categorización y cada cierto tiempo en Chile, tiende a actualizarse Un debate sobre la posibilidad de discernir y asumir las consecuencias de un acto delictivo.

La discusión respecto de los modelos de intervención para enfrentar dicha problemática ha estado centrada en la prevención, la disminución de actos delictivos y el "reencauzamiento" en función de modelos denominados como "socio-educativos" (Servicio Nacional de Menores [SENAME], 2007). La violencia y el abuso sistemático al interior de los mecanismos institucionales han sido develadas y constatados por el reciente informe denominado "Análisis del funcionamiento residencia en centros dependientes del Servicio Nacional de Menores" (Policía de Investigaciones de Chile [PDI], 2018). Una de sus conclusiones indica que:

“... es posible afirmar que en el 100\% de los centros que administra el Estado a través del Servicio Nacional de Menores, se han registrado - de manera permanente y sistemática- acciones que lesionan gravemente los derechos de los niños, niñas y adolescentes dependientes de tales centros" (PDI, 2018, p. 240).

Dicho informe interroga las responsabilidades gubernamentales concernientes a la misión socioeducativa explicitada por Sename (2007), reabriendo el debate en torno al cumplimiento de los objetivos institucionales y su articulación en un marco de derechos. Esto constituye un circuito complejo en términos jurídicos, sociales y terapéuticos. 
En este contexto, a partir del año 2006 y a través de los Programas de Sename para la atención de adolescentes infractores de ley, se establece una fase marcada por la aplicación de la Ley $\mathrm{n}^{\circ}$ 20.084, denominada Ley de Responsabilidad Penal Adolescente, que instaura un Sistema de Responsabilidad Penal de Adolescentes por Infracción a la Ley Penal. Esto implica un escenario de tránsito, en que concluye la aplicación de una justicia de corte tutelar para dar paso a la instalación de un sistema especializado de justicia juvenil. (Sename, 2007). En dicho escenario, el énfasis estaría puesto en la noción de responsabilidad, materializada en las dimensiones educativa y de integración social (Sename, 2007).

Este relativamente nuevo sistema de Responsabilidad Penal abarca adolescentes entre 14 y 18 años y entre sus particularidades se encuentra la eliminación del “discernimiento", el derecho a defensa, el debido proceso a ser oído, a la separación de los adultos y la excepcionalidad de la privación de libertad como última medida, además del apoyo a la familia del joven involucrado durante todo el proceso. El objetivo general de esta nueva Ley de Responsabilidad Penal Adolescente consiste en "hacer efectiva la responsabilidad de los adolescentes por los hechos delictivos que comentan, de tal manera que la sanción forme parte de una intervención socioeducativa amplia y orientada a la plena integración social”. (Ley n² 20.084, 2005).

El contexto graficado anteriormente resulta actual e interesante, más aún cuando la agenda de seguridad del gobierno de Chile busca instalar un proyecto de ley que posibilite el control de identidad a "menores" de entre 14 y 18 años de edad. Se trata de una legislación que apunta a ampliar el campo de atribuciones de los mecanismos de seguridad por sobre cierto espacio de intimidad y derechos individuales. El adolescente es descrito discursivamente como responsable de sus actos y a la vez, susceptible de control, articulando de forma explícita las nociones de responsabilidad, delito y control. 
La propuesta legislativa que busca reducir la edad para realizar controles preventivos podría concebirse, siguiendo a Foucault (2002), como una modalidad discursiva de instalar un sujeto delictivo, es decir, aquel que podría detectarse como tal bajo cierto régimen antes incluso de cometer cualquier acto delictual, teniendo como efecto en el campo social, la instalación de una continuidad naturalizante entre adolescente-sujeto delictual. En todo caso, no todo adolescente resulta capturado de igual forma en dicha lógica discursiva.

El marco en el cual se circunscribe la discusión en torno a la Responsabilidad Penal Adolescente está definido por el establecimiento de un criterio etario cuya tendencia es a reducirse cada vez más en el tiempo. Esta direccionalidad desplaza, si no, invisibiliza distintas tensiones, por ejemplo, la planteada por Marty (2009) relacionada a la responsabilidad de los adultos en torno a los “menores”, discusión que según Aceituno (2009), desembocaría en situar la responsabilidad de lo social en el asunto.

¿Cómo entender esta responsabilidad de "lo social" en la clínica psicoanalítica con adolescentes?, ¿Qué puntos de convergencia existirían entre la responsabilidad del adolescente respecto de sus actos y la responsabilidad del psicoanalista en su escucha?

Es en una clínica que interrogue lo social donde pueden encontrarse, subjetividad adolescente y la responsabilidad atribuible a un lugar de escucha del inconsciente, lugar del psicoanalista. A su vez, la impronta de Lacan (2010) referida al inconsciente, en tanto su estatuto es ético, permite situar la pregunta por la responsabilidad del adolescente y del psicoanalista en tanto encarna en su escucha, un lugar en lo social.

La noción de responsabilidad en psicoanálisis debe ser situada no sólo en el marco de una ley jurídica, independiente de su énfasis preventivo, punitivo o retributivo. Ante todo, el psicoanálisis como dispositivo de escucha que opera en transferencia entre un analizante y el psicoanalista, 
responde a una lógica donde la función de la ley debe considerarse principalmente en tanto ella "regula" una determinada modalidad de posiciones e intercambios, es decir, cuenta por sus efectos simbólicos. Se trata de una ley que, sin explicitarse, opera a través de mecanismos de inscripción y transmisión.

\section{Aportes desde el Psicoanálisis al acto delictual}

\section{Freud y el sentimiento de culpa}

La problemática de la delincuencia juvenil ha sido abordada desde distintas perspectivas dentro del psicoanálisis. Una primera referencia en torno al actuar delictivo está dada por Freud (1916) en su texto "Los que delinquen por conciencia de culpa". Aquí se establece la relación entre prohibición, acto delictivo y alivio anímico, dando cuenta de las motivaciones inconscientes que podían rastrearse a la base de dichos actos.

La falta cometida provendría de una acuciante conciencia de culpa que asedia al sujeto, ésta tendría relación directa con los componentes edípicos, específicamente con los “dos grandes propósitos delictivos, el de matar al padre y el de tener comercio sexual con la madre”. (Freud, 1990a, p. 339). El punto que resulta interesante en dicha perspectiva freudiana está dado por la inversión de la matriz, delito ergo culpa, dando paso al circuito: sentimiento de culpa - acto delictual. Se trata de un primer gesto subversivo que apunta a una causalidad inconsciente, puntualizando la necesidad de obtener castigo por el delito edípico, aquel que acontecería en primera instancia como propósito delictual inconsciente.

Freud (1990a) no reduce todos los actos delictivos a la matriz edípica, señalando un par de excepciones en las que no necesariamente el sujeto actuará movilizado por dicha conciencia culposa, sino más bien porque "no ha desarrollado inhibiciones morales o porque en su lucha contra la sociedad se creen justificados en sus actos” (Freud, 1990a, p. 339). De todas maneras, Freud (1990a) 
logra establecer un marco comprensivo fijando una relación entre la necesidad punitiva y ciertas causas psíquicas inconscientes, dejando lugar así a las causas, siempre particulares, que pueden alentar a cada sujeto.

La instancia superyoica plantea una doble característica, de modelo y de prohibición. Su vínculo (el del superyó) con el yo no se agota en la advertencia: “Así (como el padre) debes ser, sino que comprende también la prohibición: Así (como el padre) no te es lícito ser” (Freud, 1992a, p.36). Esto entrega pistas importantes en la medida en que en la adolescencia se pone en juego fuertemente una instancia "reguladora" del intercambio, el Ideal del yo, aquella instancia simbólica que rige una modalidad de relación al Otro. "El ideal del yo, de Freud, se pinta en esa máscara compleja y se forma, con la represión de un deseo del sujeto, por la adopción inconsciente de la imagen misma del Otro" (Lacan, 2002; p. 732).

Lacan (2002), siguiendo a Freud, puntualiza que sería la represión de un deseo lo que permitiría adquirir, de forma inconsciente, una imagen del Otro en el cual vendría a articularse un Ideal de goce del Otro ${ }^{1}$. A su vez, Hartmann (2000), puntúa que el análisis de dicho Ideal podría establecerse estrictamente en función de aquello que se recupera respecto de lo perdido en relación con el Ideal parental, deteniéndose este análisis en una dimensión más bien especular, imaginaria, es decir, situada en una relación dual, que iría del yo al otro. Esta postura enfatiza en los elementos yoicos, privilegiando aspectos como la frustración y la agresividad por sobre el posicionamiento y la herencia del sujeto respecto de un ideal.

Escuchar los actos delictivos desde un plano puramente penal/punitivo, o bien en una dimensión imaginarizada plantearía ciertas dificultades clínicas. Según Hartmann (2000), los efectos

\footnotetext{
${ }^{1}$ Otro (mayúscula) es utilizado siguiendo la distinción de Lacan (2001) respecto del otro (proyección imaginaria del yo). El Otro remite a la alteridad radical representado por el lenguaje y la ley, constituyendo el orden simbólico, lugar de donde viene la palabra para todo sujeto hablante. En esta distinción, el Ideal de goce del Otro, remite a una modalidad particular de satisfacción atribuida como predominante en el Otro.
} 
de dicha concepción podrían situar la transferencia en torno del amor o de la agresividad, siendo este el lugar donde se producen los mayores impasses, muchas veces insuperables para la dirección de la cura con adolescentes. La posible responsabilidad del adolescente por sus actos se tejería en un espacio donde no sólo está en juego la relación al delito, sino la posición desde el cual éste actúa y eventualmente, la dirección de un mensaje destinado a un Otro.

En Freud (1990a), la culpa presenta una paradoja, en la medida que es aquello que posibilita el establecimiento de un lazo social, pero es a la vez lo que podría conducir al sujeto, especialmente al adolescente, por una "expiación culposa" a producir un acto que lo conflictué con la ley, estableciéndose efectos judiciales y psíquicos. Atender el conflicto que plantea esto en el sujeto es, dar paso a la pregunta de ¿cómo se sitúa en relación con la ley simbólica?, aquella que organiza las posiciones, por ejemplo, en una estructura familiar. Desde este lugar, culpa y responsabilidad tendrán distintos estatutos en el sujeto, aunque en ambos estaría impresa una modalidad deseante.

Freud, desarrolló ampliamente la noción de sentimiento de culpa, ligado a la neurosis obsesiva, la melancolía y a la noción de "instancia censuradora" o "instancia crítica" (Freud, 1990b, p. 245246) poniendo el énfasis en su estatuto de reproches inconscientes de deseos edípicos. Durante distintos pasajes de su obra, el operar psicoanalítico tendría relación con hacer conscientes dichos sentimientos inconscientes ligados al juicio y al castigo, sin embargo, la pregunta respecto de la noción de responsabilidad presenta un tratamiento posterior y mucho más acotado.

Freud (1992b) plantea la interrogante por la responsabilidad relativa a aquellas formaciones del inconsciente, preguntándose: “¿Debemos asumir la responsabilidad por el contenido de los sueños?” (Freud, 1992b, p. 134) Dicha interrogante es situada en un plano moral, definiendo que lo socialmente, categorizado como "buenas o malas aspiraciones", conciernen al sujeto en las distintas manifestaciones en las que éstas se expresen. El sujeto está irrenunciablemente implicado en dichas 
formaciones, pese a que se trata de un saber inconsciente, no queda eximido de ninguna responsabilidad moral.

La pregunta por la responsabilidad respecto de los actos tiene en psicoanálisis un estatuto distinto de la responsabilidad por una formación inconsciente. En Freud (1992b) existe un primer esbozo de diferencia entre culpa y responsabilidad, muy asociado a la trama edípica, donde la concepción del delito se inscribe como una necesidad inconsciente de castigo ante los deseos incestuosos. En la dirección instalada por Freud (1992b), que instala un movimiento en torno a la moral y al deseo como ejes de lectura, será posible situar aportes posteriores para abordar la responsabilidad del adolescente más allá de un marco estrictamente punitivo.

\section{El papel del ambiente en Winnicott}

Otra perspectiva psicoanalítica destacable es la de Donald Winnicott, siendo su texto "Deprivación y Delincuencia" (1954) y sus estudios sobre el Desarrollo Emocional referentes ineludibles en la materia. Para Winnicott (1990) el delito cumpliría una funcionalidad psíquica en tanto implica una esperanza, así lo puntualizan Perez \& Saffie (2006), se trata de una búsqueda por parte del sujeto de la restitución del daño causado por parte del ambiente.

Esta primera referencia tiene puntos de convergencia y discontinuidad respecto de la postura de Freud, en la medida que Winnicott le asigna a la organización sexual infantil un rol preponderante respecto de la relación al delito. Sin embargo, una diferencia clara es que el énfasis de Freud apuntaría a un conflicto edípico más bien "intrapsíquico”, y el énfasis winnicottiano estaría puesto en un conflicto con el ambiente, al modo de una deprivación. Al respecto dirá: "En la base de la tendencia antisocial siempre hay una deprivación. Quizás haya consistido simplemente en que, en un momento crítico, la madre se hallaba deprimida o en un estado de retraimiento, o bien se desintegró la familia." (Winnicott, 1990, p. 180). 
Por una parte, el medio social tendría una determinada responsabilidad en captar tempranamente conductas “antisociales” que según Winnicott (1990), antes de poder atribuírseles cualquier tipo de "beneficio secundario", hablarían del riesgo de que un joven llegue incluso a transformarse en un psicópata. Por otro lado, existiría en el niño, una cierta "percepción que su tendencia antisocial se originó en una falla ambiental en el soporte del yo" (Winnicott, 1990, p. 89).

La temprana percepción en el niño de la denominada falla ambiental constituye un punto en el que podría situarse la responsabilidad en el adolescente. Muy precozmente el niño toma noticia que, en el otro, especialmente en la madre en tanto "ambiente facilitador", están dadas ciertas condiciones para desarrollar un lazo confiable con el otro. Si algo de este lazo estructurante se ve alterado, el niño agenciará una reorganización psíquica apoyándose en diversas modalidades defensivas.

“El niño empieza a recobrar las esperanzas y organiza actos antisociales, esperando compeler así a la sociedad a retornar con él a la posición en que se hallaban ambos cuando se deterioró la situación y a reconocer el hecho”. (Winnicott, 1990, p. 75)

Este espacio donde el niño o el joven formula actos, que siguen la estructura de un pedido, instituirá una implicación en ellos. Esta definición concierne tanto al medio social como a una temprana posibilidad en el niño articulando la responsabilidad en torno a un espacio con características bastante definidas. Winnicott (1990) ilustrando con casos clínicos, incita a madres de jóvenes adolescentes que han incurrido en robo a instalar en dichos actos elementos ligados a un deseo, una demanda y un derecho señala:

"Dígale que usted sabe que él no roba porque desee o necesita lo que roba, sino porque busca algo a lo que tiene derecho: está formulando una demanda a su madre y padre, pues se siente deprivado de su amor" (Winnicott; 1990, p. 83). 
Así, la puesta en juego de la responsabilidad del joven, dadas las condiciones ambientales necesarias, podrá tomar dirección en el sentido de una demanda, articulándose a través de un pedido y del ejercicio de un derecho, algo que ha sido tramitado a partir de un acto transgresor. Winnicott (1993) plantea esta modalidad como un derecho que se restituiría a partir de una palabra que encuentra lugar en tanto el ambiente y el otro produzcan las condiciones necesarias.

Winnicott (1954) en distintos pasajes de su obra pone en entredicho que el psicoanálisis sea el tratamiento adecuado para sujetos en que lo que prima es la tendencia antisocial. Sin embargo, esto no es equivalente a decir que los psicoanalistas no tendrían nada que hacer al respecto. Se trata más bien de interrogar ¿qué función pudiese tener éste en un marco donde se precisa que acontezcan movimientos subjetivos que posibiliten una relación novedosa al otro en el contexto delictivo?

La propuesta winnicottiana apunta a distintos niveles de la responsabilidad por el acto delictual. Por un lado, la provisión de un ambiente que propicie aquello truncado en distintos momentos del Desarrollo Emocional del niño. Extrapolado a una lectura contemporánea, interroga como el aparataje institucional, el estado o su representante Sename, pudiese leer esta dimensión del delito implicándose en mayor o menor medida en aquello que el joven, según Winnicott (1990), ha sido despojado en momentos cruciales de su desarrollo.

El reconocimiento de que determinadas condiciones no han sido las propicias para la organización psíquica saludable del niño constituye un gesto iniciático. Dicha postura subvierte la lógica delito-responsabilización por una matriz donde el ambiente o el otro precedente con el que se vincula el joven, ocupan un papel fundamental.

Por otra parte, si la tendencia antisocial implica una cierta esperanza, apelaría a una responsabilidad por el lado del analista quien, según Winnicott (1990) estaría o no a la altura de un encuentro en aquel momento de esperanza del joven. Este momento coincide con aquello que genera 
inconvenientes tanto a la sociedad, como al lugar mismo del psicoanalista, en la medida que se trata de actos repetitivos y transgresores, pero que, a su vez, serían vitales para que lo no dicho, inscrito y/o reconocido como deseo inconsciente pueda alcanzar dicho estatuto.

\section{Acto, actuaciones y acting out desde Lacan}

Las interrogantes posibles respecto de los actos en Psicoanálisis no se reducen ni a la mera acción motriz, ni a una conducta intencionada, más bien apuntan a una dimensión paradojal, sorprendente y significante en la que se enmarca el sujeto en tanto deseante. Por otra parte, el acto puede leerse también como aquello que se presenta en un registro distinto de la palabra, o dicho de una manera más precisa como señalan Bloch \& Von Wartburg (2004), como aquello que se articula al modo de una palabra que no puede ser dicha.

La multiplicidad de variantes que nos plantean los actos en psicoanálisis abre la pregunta por diversas formas de relación al Otro, que pudiesen estar marcada por la direccionalidad de un mensaje, o bien por un cierto "impasse" que transgrede la lógica significante. Lerude (2017) se refiere a las actuaciones en la adolescencia, distinguiendo cuatro modalidades; la oposición, la inhibición, el paso al acto y el acting out. Dichas actuaciones "están inmersas en una compleja dependencia con los actos de los padres, los cercanos y sus discursos”. (Lerude, 2017, p. 29). Es decir, las actuaciones del adolescente están en estrecha relación con los actos de aquellos que encarnen el Otro social.

Hartmann (2000) señala que todo un tratamiento analítico en jóvenes puede transcurrir muchas veces vía acting out, lo que plantea un obstáculo permanente para dicha práctica. A diferencia del paso al acto, que para Lacan (2004), implica claramente una salida de escena, analogable a la estructura de fuga o borramiento del sujeto, el acting out se presenta para ser leído, más no interpretado. Su operar resulta complejo de atender, sin embargo, puede contribuir a situar la responsabilidad del adolescente respecto sus actos delictuales. 
El acting out tiene una estructura de llamado al Otro, lugar desde donde se constituye como sujeto hablante. Puede pensarse como una denuncia presentada al modo de una mostración ante un Otro que no escucha. Emerge cuando algo de la palabra no logra establecerse con toda su eficacia, así, algo que no logra hacerse audible, se direcciona como mensaje al Otro al modo de un acto.

Si bien, como puntualizara Freud (1990a), no todo acto delictivo responde a la misma matriz, ciertos delitos pudiesen responder a una estructura de mensaje dirigido. Estos actos son muy comunes en los adolescentes tanto en transferencia como fuera de esta, padres que no escuchan, analistas que interpretan precipitadamente, tribunales que sancionan, colegios que excluyen. Si en la estructura del acting out el mensaje se constituye con una direccionalidad es porque habría algún lugar posible de ser destinatario de esa modalidad de acto. Es decir, paradójicamente, en la misma estructura del acting out en el adolescente podrían encontrarse las condiciones de posibilidad para estructurar una palabra. Esto en un marco del deseo y la ética psicoanalítica.

Lacan (2004), señala que el acting out no es interpretable, en la medida que no se rige estrictamente por la lógica significante, sin embargo, apela a una doble implicación, lugar de un lazo posible. En un tratamiento analítico la implicación por el lado del adolescente podría escucharse en la persistencia en un intento de cura cuya direccionalidad no siempre resulta del todo conocida. La pregunta por un acting out podría ser articulable sólo en un a posteriori, siempre y cuando se posibilite una escucha que haga diferencia respecto de aquellas condiciones en que aconteció como tal.

En la clínica con adolescentes en conflicto con la ley no es poco común escuchar la pregunta ¿para qué continuar un tratamiento si todo sigue igual? Se trata de una constante puesta a prueba de su interlocutor, de aquel que oficia como destinatario de su mensaje, sin embargo, esto constituiría a la vez una posibilidad de situarse respecto de un hacer repetitivo en el que está concernido. Lo 
relevante de escuchar esta pregunta es que se dirige como palabra a un Otro y que, a su vez, plantea lo incesante que el adolescente puede ser respecto de su demanda de ser escuchado.

Las preguntas esbozadas por los adolescentes presentan una cierta fragilidad en su articulación, sin embargo, es en ese mismo espacio de tensión subjetiva donde puede esbozarse algo del orden de su responsabilidad. La posibilidad de que el analista esté a la altura de escuchar dicha interrogante, en un espacio transferencial siempre frágil, posibilitaría o no al adolescente implicarse en lo que le competen sus actos, que no necesariamente se ligan directamente al delito. Esto nos hace entrar en la responsabilidad del analista y cómo su lugar está marcado por una posición ética y deseante.

\section{La responsabilidad del analista; ética y deseo como dirección}

Chemama (2018) despeja algunas verdades poco cuestionadas en el marco de lo que Freud denominara como "abstinencia del terapeuta". Un primer asunto remite al entendimiento de dicha premisa como "neutralidad del analista”. Es preciso señalar que dicha mención alude más bien a la atención flotante del analista, es decir, a la no orientación de la cura en base a sus propios prejuicios, dejando en suspenso una moral regida estrictamente por el bien y el mal. La confusión respecto de dicha impronta freudiana podría llevar al analista a la imposibilidad de escuchar aquello que surge de manera sorpresiva, al modo como diría Lacan (2010), de una apertura del inconsciente. Momento fecundo para la palabra y la responsabilidad por la posición subjetiva.

La estrecha relación entre actos delictivos de adolescentes en conflicto con la ley y una lógica regida por el inconsciente, entrega pistas para abordar la responsabilidad del analista. Chemama (2018) otorga un lugar fundamental a esto señalando que: "Es sólo en la cura, de cierto modo, cuando el inconsciente se constituye plenamente, al mismo tiempo que se revela." (Chemama, 2018, p.105). De dicho planteamiento se deduce que para que la posible articulación de un acting out, en su 
dimensión de palabra no dicha, tenga lugar, no sólo apela un Otro disponible a escuchar, sino que la presencia de éste sería una condicionante de la revelación y constitución del inconsciente.

La responsabilidad del analista estaría comandada por la puesta en juego de un deseo que se plantee, siguiendo a Lacan (2007), no cediendo ante aquello que teniendo la estructura de palabra no dicha pueda hacerse audible, es decir, restituyendo en el acto una dimensión de palabra. Se trata no sólo de un acuso de recibo, sino de un posicionamiento ético, en la medida que aquel mensaje dirigido escapa del campo de la comprensión y se resiste a entrar plenamente en el campo de la interpretación analítica.

Si bien Freud (1990a), señala que no todo acto delictivo necesariamente opera en base a motivaciones inconscientes, la hipótesis de que en dichos actos pueden estar presente, aspectos inconscientes, debe considerarse seriamente. Se trata de situar en transferencia las condiciones para que la palabra emerja en la clínica del adolescente en un contexto delictual. Este es un punto de encuentro entre la responsabilidad del analista y la responsabilidad del adolescente.

Los actos de los cuales un adolescente podría responsabilizarse se gestan y a su vez, tienen repercusiones y consecuencia en el lazo social, por lo tanto, los distintos niveles de delitos en un determinado marco de conflicto con la ley, posibilitarán diferentes direcciones de tratamiento y escucha. Considerando que dichos actos involucran a otro, el cómo se sitúa el psicoanalista respecto de la ley jurídica no resulta ser un dato anecdótico. La sanción penal o eventual impunidad jurídica del delito serán aspectos a considerar en la toma de posición del psicoanalista, aquí la dificultad recaería en ¿cómo establecer criterios, no meramente punitivos para escuchar aquello que emerge como responsabilidad en un adolescente que delinque? De esta forma la ley jurídica es una referencia no menor, pero bajo ningún caso aquello que determinará la dirección de la cura en dichos casos. 


\section{Discusión}

El modelo de administración de justicia en lo que atañe a la Ley de Responsabilidad Penal Adolescente (2005), parte de dos supuestos básicos que el psicoanálisis viene a poner en entredicho. El primero de ellos es que el énfasis de dicha ley apunta a que el sujeto se responsabilice por el delito cometido, enfatizando la dimensión jurídico-penal e instalando de entrada la superposición entre responsabilidad y delito. Dicha perspectiva interroga en menor grado en qué consistiría una responsabilidad que aborde lo que Winnicott (1993) define como papel de ambiente, o que considere los aportes de Lacan (2007) en lo concerniente al Otro en su dimensión ética y deseante.

Un segundo punto es el supuesto de que la responsabilización por el delito cometido abriría paso a la posibilidad de ser educado. Ya Freud atendiendo al conflicto entre las exigencias pulsionales y las restricciones culturales, plantea en su texto de 1930, "El malestar en la cultura", tres oficios imposibles: gobernar, educar y analizar. ¿Cómo considerar esta afirmación? El tratamiento dado a la problemática de la delincuencia adolescente es una cuestión donde precisamente convergen los tres imposibles freudianos, en la medida que responden a políticas gubernamentales de estado cuya finalidad última apuntaría a educar a un sujeto que trasgrede la ley. Sumado a esto, una tentativa de tratamiento psicoanalítico, ¿configura todo esto un cuadro imposible?

Atender a aquellas profesiones que Freud situara como imposibles es atender a que estas no pueden ser llevadas a cabo sin impasses, es decir, que serán siempre excedidas respecto de cualquier tipo de conocimiento, lógica o ética basada en el supuesto de que un sujeto puede ser domado absolutamente en su ejercicio pulsional. Se trata de pensar una relación analítica en un marco de posibilidades donde el deseo y la ética del analista se encuentran interpelados.

Si bien el trabajo de escucha del analista y su responsabilidad estarían marcados por una neutralidad no enjuiciadora de aquello que conduce los actos delictivos, dicha posición no se 
reduciría a esto. Es a través de las actuaciones y/o acting out como un adolescente podría dar cuenta de una palabra que no ha sido articulada, y es aquí precisamente donde la posición del psicoanalista tendría consecuencias no menores respecto de la posibilidad que un adolescente se entregue o no a un trabajo psicoanalítico, lugar donde la palabra podría adquirir un estatuto novedoso.

No se trataría puramente de dar lugar a aquello que no lo ha tenido en tanto escucha. En una clínica atestada de impasses, imposibilidades y acting out, es decir, que pone en juego toda una serie de aspectos necesarios para que la cura fracase, la responsabilidad del psicoanalista tendrá relación con la puesta en juego de su deseo en tanto dirección fundamental de la cura. Este es el recorrido establecido por los aportes de Freud, Winnicott y Lacan, quienes respectivamente contribuyen a, resituar el lugar de la culpa, cuestionar una lógica binaria delito-responsabilización del adolescente introduciendo una matriz donde el ambiente o el otro social son fundamentales y, finalmente, a orientar el trabajo clínico en función de una ética y una puesta en juego del deseo del psicoanalista.

El deseo del psicoanalista, en la particularidad de esta clínica, no sería un deseo cualquiera en la medida que constituye una condición de posibilidad, la única vía, para que cualquier elemento asociado a la responsabilidad del adolescente por sus actos y ante todo por su posición sexual / social, comience a movilizarse. Se trata, como señala Lerude (2017), del encuentro con un Otro que no se escabulla, Otro encarnado por el psicoanalista, para que el adolescente (pues sólo él puede) establecer lo ocurrido en sus actuaciones más allá de cualquier marco estrictamente punitivo. Siguiendo a Lacan (2007) respecto de una ética del inconsciente, y de la posición analítica, se trataría de una interrogante cuya dirección debiese considerar seriamente aquello en lo que no sería posible ceder en la escucha clínica de adolescentes en conflicto con la ley: Una posición ética y su deseo como dirección. 


\section{Referencias}

Aceituno, R. (2009). "Responsabilidad y justicia de menores. Entrevista a François Marty.” En Revista de Psicología Universidad de Chile. Volumen 18, Núm. 1. Recuperado de: https://revistapsicologia.uchile.cl/index.php/RDP/search/search

Bloch, O. \& Von Wartburg, W. (2004): Dictionnaire étymologique de la langue francaise, Paris: Presses Universitaires de France.

Chemama, R., Lacote-destribats C. \& Vandermersch, B. (2018). El Oficio del psicoanalista. Buenos Aires- Bogotá: Editorial Logos Kalós.

Foucault, M. (2002) Vigilar y castigar. Nacimiento de la prisión. Buenos Aires: Siglo XXI.

Freud, S. (1990a) Los que delinquen por conciencia de culpa (1916). En Obras Completas, Vol. XIV (pp.338-340). Buenos Aires: Amorrortu.

Freud, S. (1990b) “Duelo y Melancolía” (1917 [1915]). En Obras Completas, Vol. XIV (pp.235256). Buenos Aires: Amorrortu.

Freud, S. (1992a). "El yo y el ello" (1923). En Obras Completas. Vol. XIX (pp.1-66). Buenos Aires: Amorrortu.

Freud, S. (1992b). “La responsabilidad moral por el contenido de los sueños” (1925). En Obras Completas, Vol. XIX (pp.133-136). Buenos Aires: Amorrortu.

Hartmann, A. (2000). Adolescencia: Una ocasión para el psicoanálisis. Buenos Aires: Miño y Dávila editores.

Lacan, J. (2001). Seminario II. El yo en la teoría de Freud y en la técnica psicoanalítica. Buenos Aires: Paidós.

Lacan, J. (2002). Escritos 2. Buenos Aires: Siglo XXI.

Lacan, J. (2004). Seminario X: La Angustia. Buenos Aires: Paidós. 
Lacan, J. (2007). Seminario VII. La ética del psicoanálisis. Buenos Aires: Paidós.

Lacan, J. (2010). Seminario XI: Los cuatro conceptos fundamentales del psicoanálisis. Buenos Aires: Paidós.

Lacan, J. (2012). “Los complejos familiares en la formación del individuo. Ensayo de Análisis de una función en psicología”. (1938). En Otros Escritos (pp. 33-96). Buenos Aires: Paidós.

Lerude, M. (2017). "El paso al acto ¿puede hacer acontecimiento? La toma de partido del psicoanalista frente al paso al acto". En Cuadernos de Psicoanálisis, Clínica Psicoanalítica (5). P. 29-36.

Ley $\mathrm{n}^{\circ}$ 20.084. Establece un sistema de responsabilidad de los adolescentes por infracciones a la ley penal. Biblioteca Nacional del Congreso, Santiago, Chile, 28 de noviembre de 2005. Recuperado de: http://bcn.cl/1uvyu

Policía de Investigaciones de Chile (2018). Informe análisis del funcionamiento residencial en centros dependientes del Servicio Nacional de Menores. Recuperado de: https://m.elmostrador.cl/media/2019/07/informe-emilfork.pdf

Perez, C. \& Saffie X. (2006). Aportes desde el Psicoanálisis al problema de la delincuencia juvenil. Análisis de la noción de joven infractor de la Ley del Sename a partir de la teoría de Donald Winnicott (tesis de pregrado). Universidad Diego Portales. Facultad de Psicología, Santiago, Chile.

Servicio Nacional de Menores (2007), Sistema nacional de atención socioeducativo para adolescentes infractores de ley, período 2006-2010. Recuperado de: http://www.sename.cl/wsename/otros/rpa/Siistema_nacional.pdf

Winnicott, D. (1990). Deprivación y Delincuencia. Buenos Aires: Paidós. 
Espinosa. Responsabilidad (penal) adolescente, responsabilidad del psicoanalista: ética y deseo como posibilidad para una clínica psicoanalítica

Winnicott, D. (1993) Los Procesos de Maduración y el Ambiente Facilitador: Estudios para una teoría del desarrollo emocional. Buenos Aires: Paidós.

Recepción: 16 de mayo 2019

Última Revisión: 27 de septiembre 2019

Aceptación Final: 20 de noviembre 2019 